\title{
Arctic and Antarctic Analogs for Planetary Surface Traverses
}

\author{
S. J. Hoffman, Ph.D ${ }^{1}$ and A. O. Cameron ${ }^{2}$ \\ ${ }^{1}$ Science Applications International Corporation, 2450 NASA Parkway, Houston, \\ Texas 77058; PH 281.483.9264; email: stephen.j.hoffman@saic.com \\ ${ }^{2}$ Intelligent Land Management, Inc., $1107^{\text {th }}$ Street, SE, Washington DC, 20003; PH \\ 202.544.6640; email: andycameron@earthlink,net
}

\section{ABSTRACT}

The proposed paper summarizes a recent (August 2009) workshop at the NASA Johnson Space Center discussing lessons learned from traverses, driven largely by science objectives, in the Earth's polar regions. These lessons will be used as one facet of NASA's preparation to explore, over extended periods of time, the surface of the Moon and Mars as part of the Constellation Program. Over 50 years of extensive traverses in both the Arctic and Antarctic provide a potentially rich source of lessons for future planetary missions under analogous conditions.

For both lunar and Mars missions it is anticipated that both crew and robotic equipment, which could arrive on different vehicles, will land in a fairly benign location. But "benign" can also translate into "uninteresting" from a scientific or exploration perspective, resulting in the crew exhausting the scientific potential of a particular site before returning to Earth. This is especially true for Mars mission crews who will spend 18 months at a given location. By providing a capability to move long distances across the surface removes the need to risk a landing at a more challenging, but interesting, surface location.

The proposed paper summarizes the workshop presentations and discusses several of the key findings or lessons including: (1) A recognition that NASA's current approach for long duration planetary surface operations has fundamental differences from any of the operational approaches described by the invited speakers. These approaches drive the crew size and skill mix to accomplish basic objectives and, in turn, drive the logistical pyramid needed to support these operations. NASA will review the operational approaches of the organizations represented to understand the differentiating factors. NASA will then decide if it should alter its current approach to surface exploration. (2) There are potential parallels between key characteristics of the systems used for exploration in these environments, such as heated volume as an analog for pressurized volume or energy usage for various activities. NASA will look at these characteristics to identify which could help with preliminary planning and gather raw data from the presenters to model these characteristics. (3) New technologies are being applied and design approaches are being tailored to take advantage of these technologies on both side. Interactions between these two communities has begun or is expanding to understand how these new technologies are being leveraged: NASA habitation designers are exchanging ideas and approaches with the Antarctic station designers; Antarctic support 
contractors have put together a list of areas where NASA could benefit from their experience and vice versa; discussions have begun to compare the equipment used for the NSF South Pole Station resupply traverses to identify possibly functional similarities for NASA.

\section{Introduction}

Extended surface traverses by human explorers on other planets has been an element of many of the planned and actual missions in this modern era of space exploration. Wernher von Braun, in his book The Mars Project (von Braun, 1962), envisioned his crew of human explorers landing on the (presumed) smooth icy planes of the Mars polar regions and then traversing to the equatorial regions (a distance of some 7000 kilometers) to set up their rockets for ascent back to their waiting Earthreturn spacecraft. The details for this book were being prepared during the early 1950 's at a time when many nations were resuming their exploration of Antarctica. This including one group of Norwegians, Swedish, and British scientists who had just completed a two-year expedition to this continent, a period of time roughly equivalent to the time spent on the surface of Mars in this notional mission. (We will return to a discussion of this group later in this paper.)

Since this plan was put forward by von Braun there have been several actual traverses on the surface of the Moon, totaling approximately 95 kilometers by 12 individuals accumulated in six separate Apollo missions, as well as numerous other plans of varying levels of detail for both shorter and longer traverses on the Moon and Mars. NASA is now actively examining how surface traverses will contribute to its overall direction for human spaceflight, namely to "establish a program to develop a sustained human presence on the Moon, including a robust precursor program to promote exploration, science, commerce and U.S. preeminence in space, and as a stepping stone to future exploration of Mars and other destinations" (Congress of the United States, 2005). During this same 60 year period over 130 separate scientific traverses accumulating tens of thousands of kilometers of travel distance several hundred individuals has been accumulated in the Antarctic (Anon., 2004, p.2-7 through 2-10). And this does not include numerous resupply traverses by the United States, the Soviet Union, and other countries that maintain inland stations.

Given this reservoir of data and lessons regarding surface traverses in very challenging environments, this paper discusses a workshop convened a the NASA Johnson Space Center to discuss lessons learned from traverses, driven largely by science objectives, in the Earth's polar regions. We anticipated that these lessons could help shape how similar traverses will be conducted by NASA and others on the lunar and Martian surfaces. There was general agreement by those representing both sides of this interaction (i.e., the polar traverse side and the planetary surface traverse side) that there were lessons to be learned by both sides but there is more work yet to be done in order to communicate and determine how best to take advantage of these lessons.

The remainder of this paper will cover three main topic areas. First will be a discussion of the current thinking within the NASA human spaceflight community regarding planetary surface traverses. While this topic currently involves both lunar 
and Mars missions, it will be Mars missions that are described in some detail given the authors' greater familiarity with Mars surface missions. The second topic area will be a description of the surface traverse workshop held at the NASA Johnson Space Center on August 4-6, 2009 along with some additional background information regarding three of the Antarctic surface traverse discussed at the workshop. The final topic area will be a discussion of the observations and key lessons learned resulting from this workshop along with plans for carrying this investigation forward into gathering more detailed data from traverses in the Earth's polar regions along with the analyses that are planned for these data.

\section{Mars Surface Traverse Options}

Candidate surface sites will be selected based on the best possible data available at the time of the selection, the operational difficulties associated with the site, as well as the collective merit of the science and exploration questions that can be addressed at the site. Data available for site selection will include remotely gathered data sets plus data from any landed mission(s) in the vicinity plus interpretive analyses based on these data.

Figure 1 illustrates a notional series of traverses to features of interest at the junction of the Isidis Planatia and Syrtis Major regions. No particular preference is being given to this site; it is included here to illustrate some general features of a human exploration mission and the resulting implications for operations at such a site.

From an operational perspective, this location has a relatively broad, relatively flat, centrally-located area where the cargo elements can land in relative safety. However this places these systems and the crew at large distances from those features that are of interest to the crew and the science teams. The scale at the lower right indicates that these features of interest are beyond what is currently considered a reasonable walking range for the crew (determined by the distance a crewperson can walk during one charge of power and breathing gases in their portable life support system - roughly 15 kilometers total). Although sites with much more closely space features of interest are certainly possible, they are usually found at the expense of a relatively safe landing site. Thus a nominal set of traverses for any of the first three human Mars missions are likely to be on the order of 100 kilometers radial distance from the landing site, and based on several notional sites including the one shown in Figure 1, these traverses could be much longer than the simple 200 kilometer round trip.

Three possible approaches to satisfying this desired combination of horizontal and vertical exploration were created during this Reference Architecture assessment. These three options, given the working titles of "mobile home", "commuter" and "telecommuter", were constructed to focus on different approaches to accomplish these two exploration "directions". It is recognized that there are other combinations and permutations of these basic functions that could also satisfy these high level goals, but given the time and resource constraints of this Reference Architecture assessment, only these three were examined. An overview of each will be discussed in the next several paragraphs. 
The "mobile home" surface mission scenario assumes that surface exploration by the crew will be primarily a mobile operation. Thus this scenario assumes the use of two (for mutual support) large, capable, pressurized rovers for extended traverses, spending between two and four weeks away from the landing site (see Figure 2). These rovers will have space and resources allocated for on-board science experiments. The landing site is assumed to have those infrastructure elements not needed for the extended traverses, such as consumables, spare parts, and a large power plant. The processing capacity of this ISRU plant is TBD and dependent to a certain degree on the assumed implementation for the rover power source (assumed to be nuclear). The landing site will be the "pantry" for food and other basic maintenance and repair capabilities as well as storage for consumables and a large power plant. As such the landing site has minimal crew habitation capabilities. With this division of functions among the surface systems, it is assumed that the crew will make a number of traverses away from the landing site, but return periodically to resupply and refit the rovers before deploying on the next traverse.

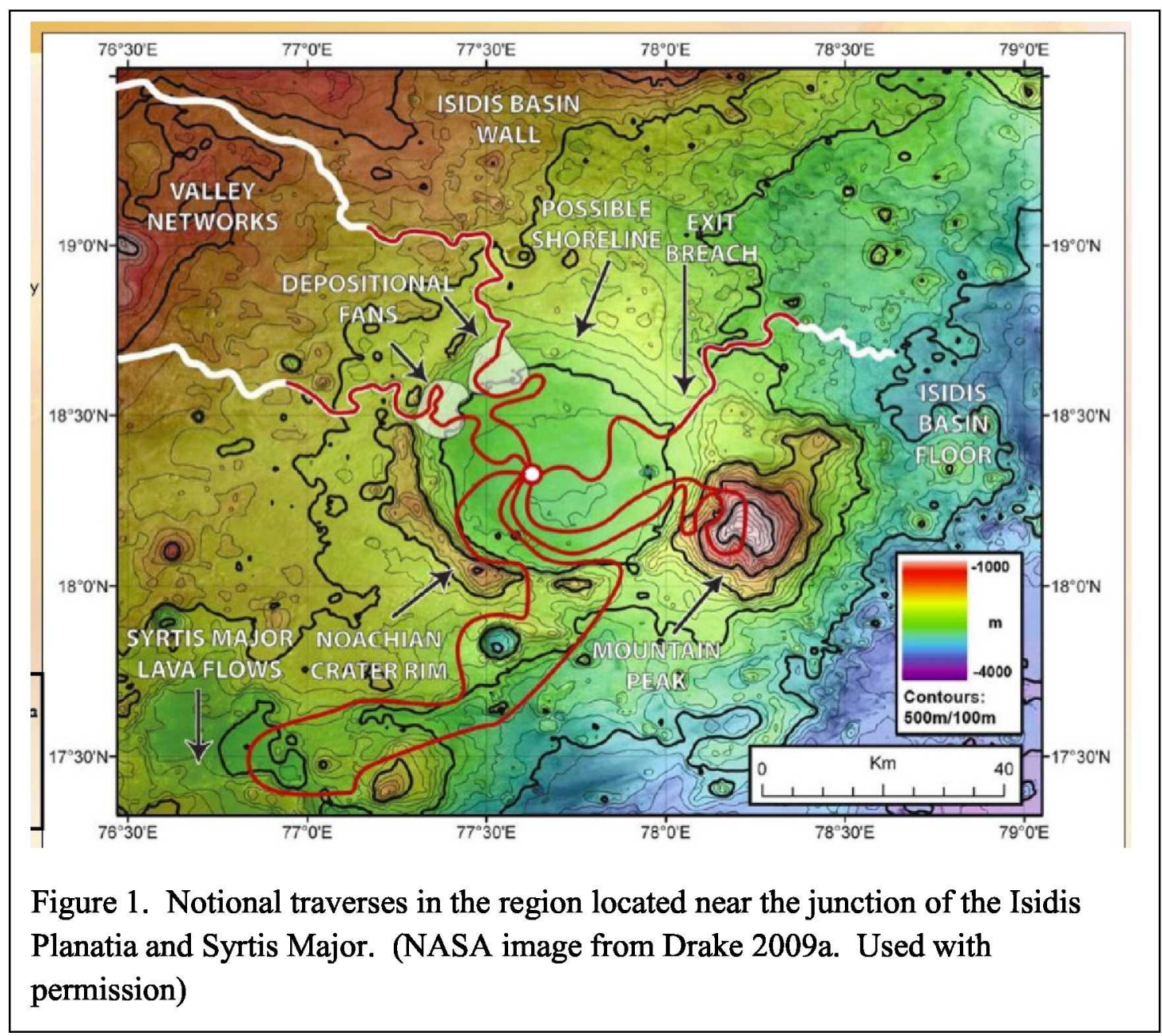

In addition to the internal science experiments mentioned above the pressurized rovers will also bring along two small robotic rovers, two unpressurized (but small - comparable to the Apollo Lunar Rover Vehicle, LRV) rovers to carry EVA crews, and a drill. The two robotic rovers can be teleoperated from the 
pressurized rover or can be given a set of instructions and allowed to carry out these instructions in an automated fashion. The unpressurized rovers will allow the EVA crews to move relatively quickly between sites within walk-back range of the pressurized rovers once the latter have stopped for extended operation at a given location (it is assumed that the pressurized rovers will not be very nimble and thus will serve as a "base camp" from which local traverses will be staged).

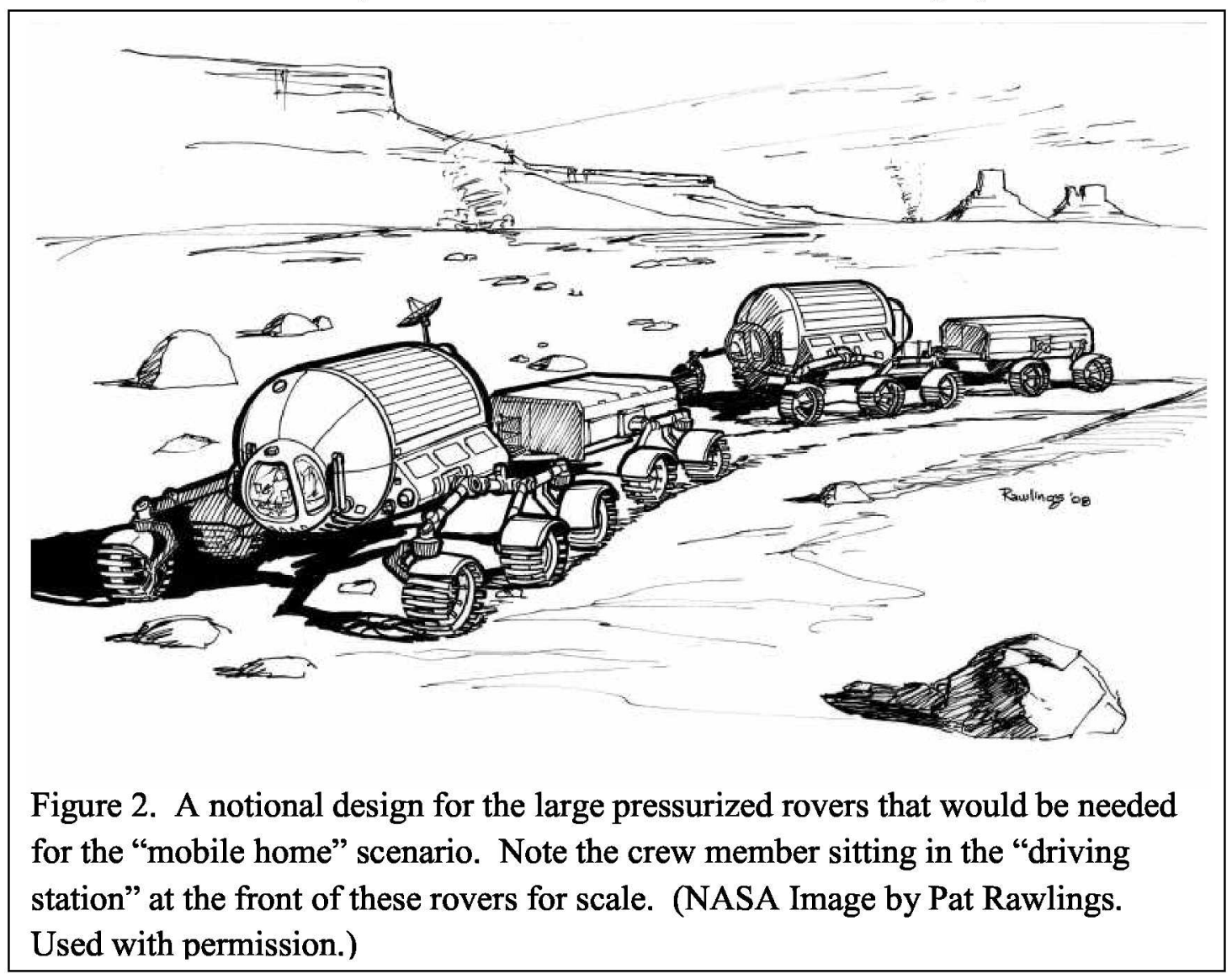

The "commuter" surface mission scenario (see Figure 3) assumed a centrally located, monolithic habitat, two small pressurized rovers, and two unpressurized rovers (roughly equivalent to the Apollo Lunar Rover Vehicle). Power for these systems will be supplied by a nuclear power plant previously deployed and used to make a portion of the ascent propellant. Although traverses will be a significant feature of the exploration strategy used in this scenario, these traverses will be constrained by capability of the small pressurized rover. In this scenario, these rovers have been assumed to have a modest capability, notionally a crew of two, 100 kilometers total distance before being resupplied, and no more than one week duration. Thus on-board habitation capabilities will be minimal in these rovers. However these rovers are assumed to be nimble enough to place the crew in close proximity to features of interest (i.e., close enough to view from inside the rover or within easy EVA walking distance of the rover). Not all crew will deploy on a traverse, so there will always be some portion of the crew in residence at the primary habitat, permanently located at the landing site. 
The primary habitat will have space and resources allocated for on-board science experiments. The pressurized rovers will carry only minimal scientific equipment deemed essential for field work; samples will be returned to the primary habitat and its on-board laboratory for any extensive analysis.

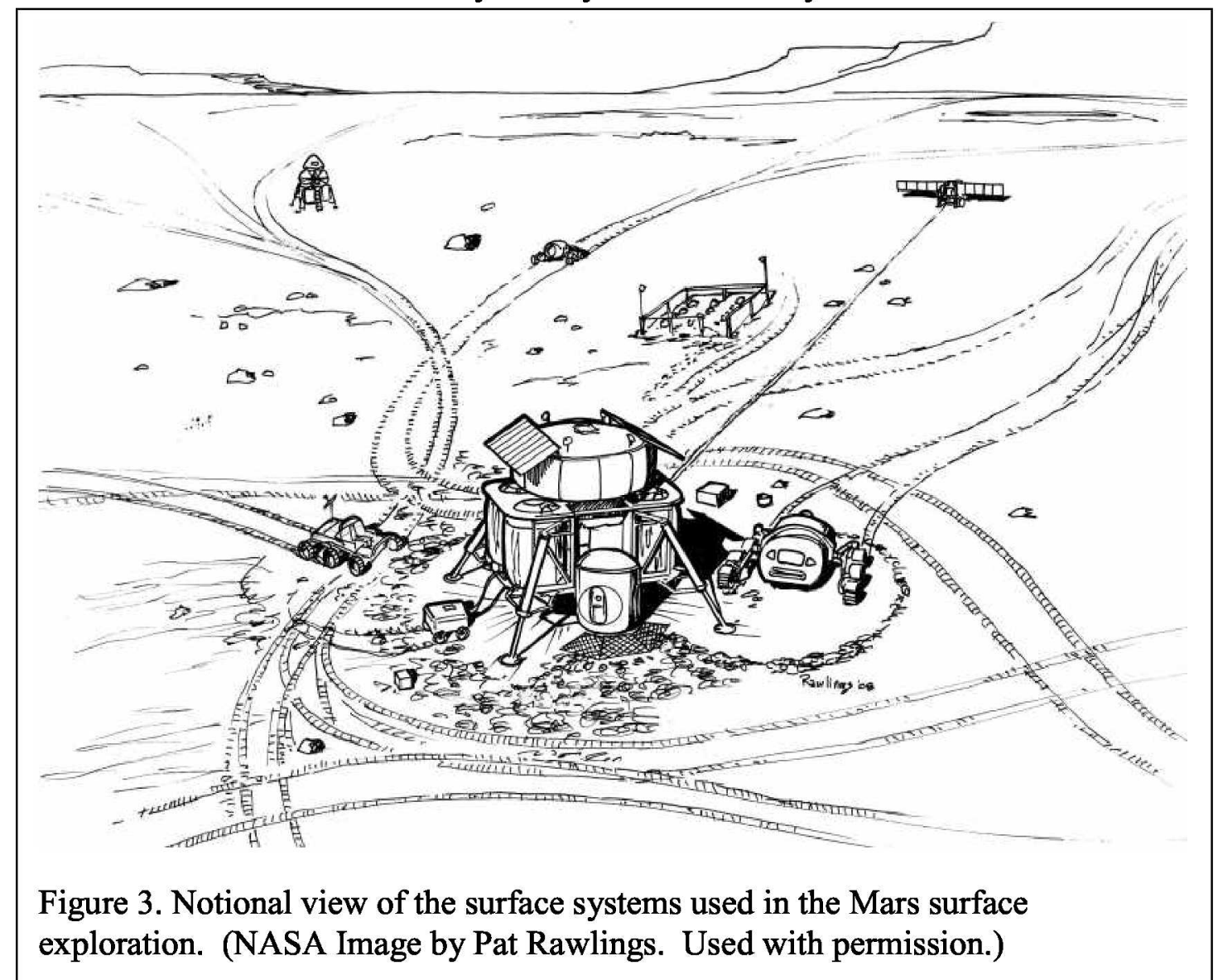

In this last case, the "telecommuter" scenario, it is assumed that the crew will be based in a centrally located, monolithic habitat and only unpressurized (lunar rover equivalents) rovers will be used for local, short duration EVAs. This implies traverses by the crew of no more than walk-back distances (approximately 15 kilometers radial distance). The long range traverses will be handled by very capable robotic rovers (notionally a considerably improved MSL rover) teleoperated (or possibly supervised) by the surface crew from their habitat (see Figure 4). Because of the assumed prepositioning of surface cargo, there is an opportunity to deploy these rovers independently from the large surface habitat (but during the same atmospheric entry event) to sites that are distant from the habitat landing site. In this situation, there will be up to two years available for these rovers to carry out long distances traverses, guided from Earth-based operators, with an ultimate destination of the habitat landing site. After the crew arrives at the habitat, these robotic rovers can be deployed on other traverses under the guidance of the surface crew.

A group of scientists familiar with the goals and objectives likely to be established for future human missions to the Moon and Mars was assembled by the Mars Exploration Program Analysis Group (a standing NASA working group often asked to address these types of questions). This group, named the Human 
Exploration of Mars Science Analysis Group, considered these three approaches and indicated a preference for the "commuter" option, although none of the approaches could be completely ruled out.

One approach to accomplishing the desired long traverses under this "commuter" scenario will be to use the pressurized rovers (or possibly robotic rovers) to prepositioning supplies in caches along the proposed route of travel prior to the "full duration" traverse. Thus a typical traverse will begin with the crew (or robotic rovers) traveling out a nominal distance (approximately 15 kilometers, or EVA walkback distance) and establishing a cache of commodities for life support and power

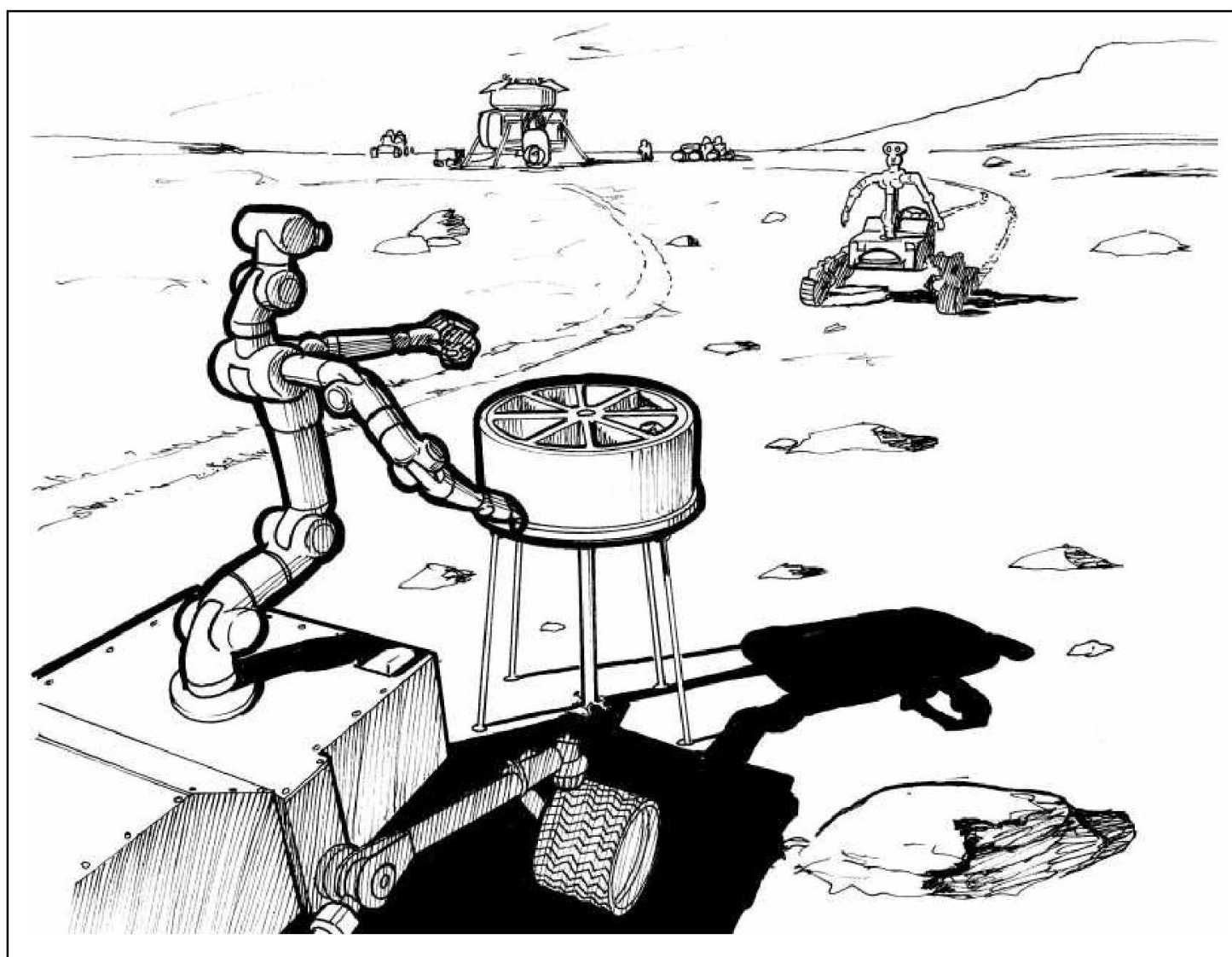

Figure 4. A notional image of teleoperated rovers operating on the surface of Mars. In this case one rover, considered "sterile" for astrobiological purposes, places a sample of potential biological material in a sterile container which can then be sealed and handled by a "contaminated" rover that operates in the vicinity of the habitat. (NASA Image by Pat Rawlings. Used with permission.)

(possibly emergency habitation) before returning to the habitat. Some amount of exploration-related activities may be accomplished during this cache deployment phase but the primary purpose is route reconnaissance and cache establishment. The crew then makes another traverse, establishing a second cache a like distance beyond the first cache. This process continues until all caches in this chain are built up sufficiently for the crew, in the two pressurized rovers, to make the entire round trip traverse for the time duration needed to accomplish traverse objectives. The amount of time required to set up and retrieve these supply caches will depend on the specific 
conditions for a traverse. However, the timeline in Figure 5 illustrates how much can be accomplished if approximately two weeks are allocated for establishing this string of caches and another two weeks to retrieve them. In addition, not all traverses will be long enough to require this type of support. A mixture of cache-supported and unsupported traverses has been illustrated. Finally, some amount of time will be required to repair and restock the pressurized rovers after each traverse, as well as

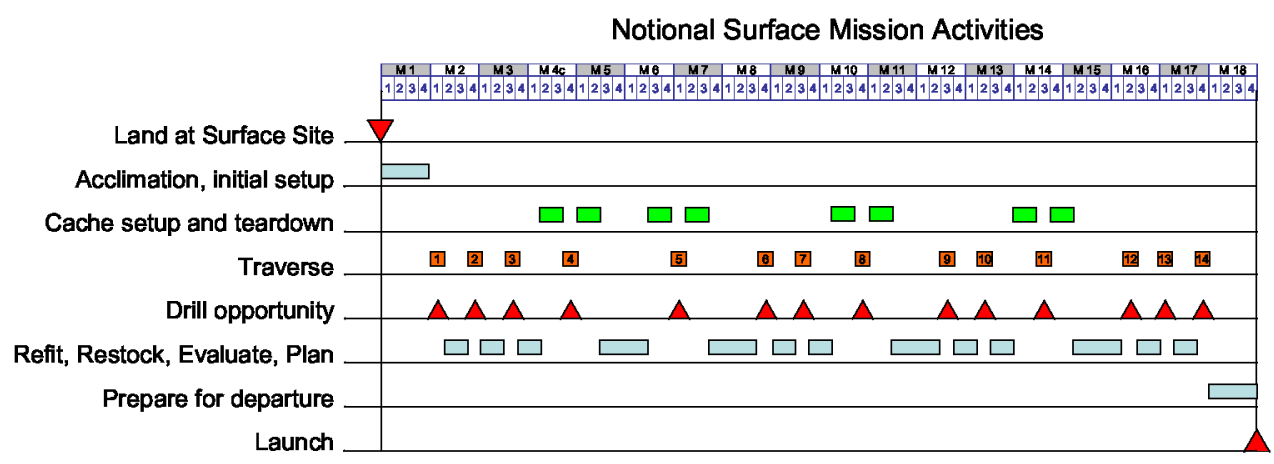

Figure 5. A notional surface exploration timeline to illustrate the number of traverses and other related activities assuming the use of small pressurized rovers of limited capability and the use of caches to extend traverse range. (Figure 6-5 from Drake, 2009b, p 253. Figure prepared by the author for the referenced report. Used with permission.)

conduct any local experiments and plan for the next traverse. A notional two weeks between short traverses and four weeks between long traverses has been illustrated in Figure 5.

\section{Workshop Summary}

The workshop was divided into two parts covering two full days. On the first day eight invited presentations were made to those attending. The second day consisted of several smaller focus meetings with specialized groups (e.g., surface rovers, EVA suits, habitats, traverse planning, etc.) to provide an opportunity for continued discussions based on the first day's presentations.

Fifty people, including the invited speakers, attended the first day's presentations. These attendees represented six different NASA Centers and several contractors or universities. The presentations consisted of: (1) Dr. Charles Swithinbank (Scott Polar Research Institute) discussing observations from the Norwegian- British- Swedish Expedition (NBSX) of 1949-52 and the evolution that followed, (2) Dr. Charles Bentley (University of Wisconsin) discussing the first of two perspectives on the International Geophysical Year and the evolution that followed, (3) Dr. Richard Cameron discussing the second of two perspectives on the International Geophysical Year and the evolution that followed, (4) Dr. Friedrich Horz and Dr. Gary Lofgren (NASA Johnson Space Center) discussing the Apollo lunar traverses and the associated planning along with contemporary field tests of 
NASA equipment and procedures, (5) Dr. Marie-Claude Williamson (Canadian Space Agency) discussing contemporary science traverses in the Arctic, (6) Dr. Mary Albert (Dartmouth College) discussing contemporary science traverses in the Antarctic, (7) Mr. John Gruener (NASA Johnson Space Center) discussing NASA's plans for potential traverses on the lunar surface in the next era, and (8) Mr. Johan Berte (International Polar Foundation) providing an overview of the Belgian Princess Elizabeth Antarctica research station and its development.

Three short summaries of these polar expeditions and their traverse experience, spanning from the very earliest to the most recent, are discussed in the next several sections. These brief summaries are provided to illustrate what was accomplished by these teams as well as providing a means to compare these activities with the proposed Mars surface exploration approaches discussed previously.

\section{Norwegian-British-Swedish Antarctic Expedition of 1949-52}

The Norwegian-British-Swedish Antarctic Expedition of 1949-52 began with Swedish scientists seeking to investigate some pre-World War II photographic data that appeared to indicate significant glacial retreat in this area (there were concerns about climate change even at this time). Unable to finance the entire expedition, Swedish scientists expanded the effort to include colleagues from Norway and England with similar interests (and additional finances; see Giaever, 1954 and Swithinbank, 1999 for additional details). With the addition of Norwegian and British scientists, objectives for the expedition also expanded to include a general survey of this region of Antarctica, which was largely unexplored at the time. This expedition spent two consecutive years completing these objectives, which included a wide range of scientific investigations in the fields of geology, glaciology, meteorology and medicine. In addition, the crew conducted significant topographical surveys and mapping of the local region. Norway was mainly responsible for meteorology and topographical surveys, Britain for geology and Sweden for glaciology. The expedition team totaled 15 men -- eight scientists (two glaciologists, two meteorologists, two geologists, a geophysicist and a topographical surveyor) and seven support personnel.

This group used much of its first Austral summer to find a suitable location near the coast of Dronning Maud Land -- an area lying between the meridians of $20^{\circ} \mathrm{W}$ and $45^{\circ} \mathrm{E}$-- where they could establish a base camp. Small aircraft were used to cover more of the coast line in a shorter period of time. Even with this assistance, it took the team until early February (late in the austral summer) to find a location along the ice front where their cargo ship could unload. Several huts, for accommodation and housing of research and communication equipment, were assembled at this base camp (christened Maudheim, located at $71^{\circ} 03 \mathrm{~S}, 10^{\circ} 55^{\prime} \mathrm{W}$ ) along with some 450 tonnes of supplies, sufficient for a stay of up to three years (to protect against the possibility of pack ice preventing the ship from reaching them at the appointed time). Another substantial camp -- Advance Base -- was sited at $72^{\circ} 17^{\prime} \mathrm{S}, 03^{\circ} 48^{\prime} \mathrm{W}$ (approximately 320 kilometers from Maudheim), close to a nunatak named the "Pyramid". This camp was not permanently occupied, but consisted of tents, stocks of food and fuel available to support field parties. This team 
also established a network of expedition-support supply depots away from Maudheim and Advance Base to allow field parties to explore for extended times and at extended ranges from either camp.

Surface traverses were conducted by means of either dog teams pulling sledges (62 dogs were part of this expedition) or by using some number of the three tracked amphibious vehicles (the "Weasel", a small tracked vehicle developed for military use during World War II, capable of transporting several people or pulling up to three tonnes of payload). Most of the reconnaissance traverses were conducted by small (two or three man) teams using dog sledges and skis. One of these teams

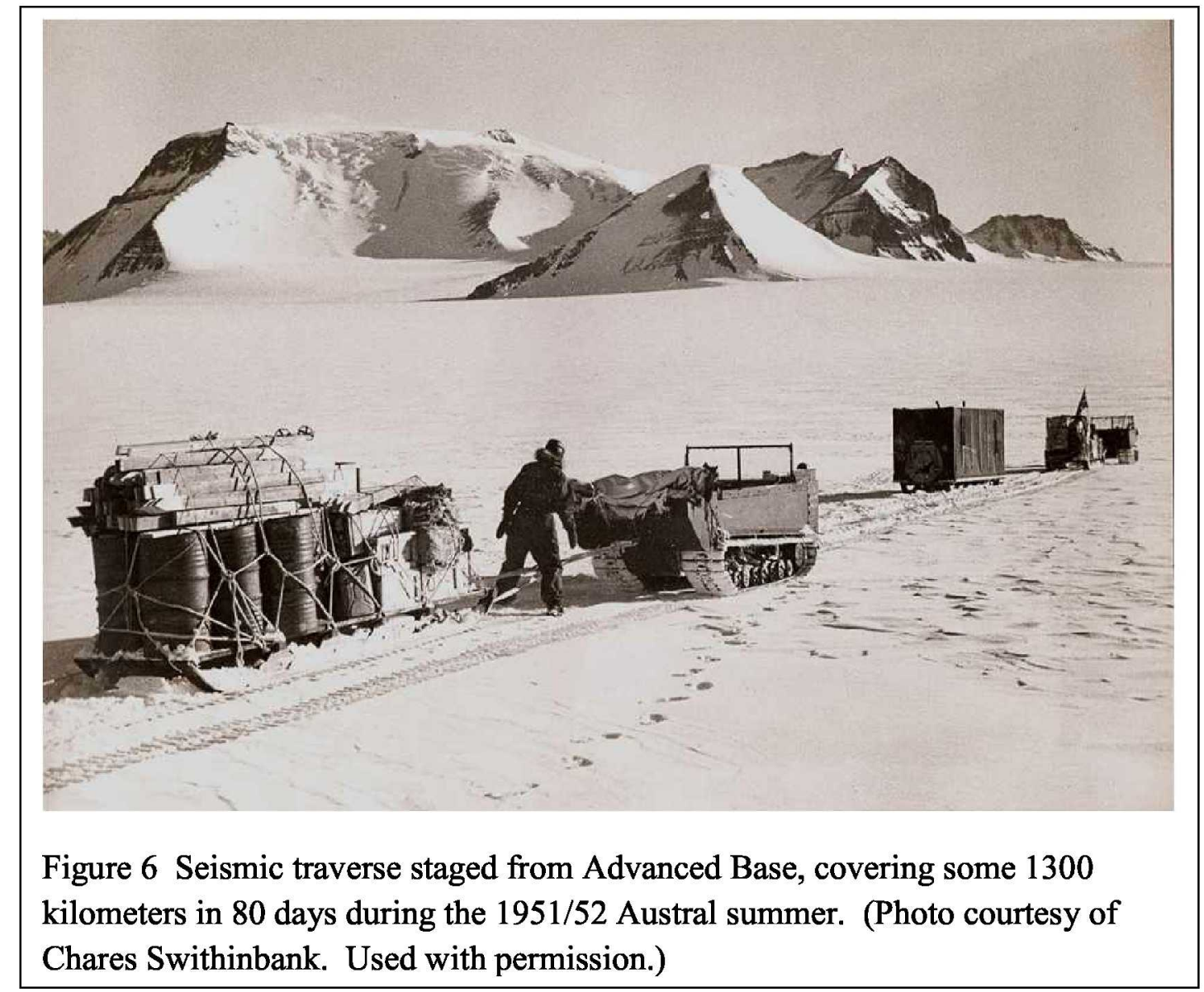

remained in the field for six months before returning to Maudheim. The Weasels were used primarily to haul heavy loads, such as the short (three kilometer) trip between the supply ship and Maudheim or the long (300 kilometers) trip between Maudheim and Advanced Base. During the 1951/52 Austral summer, two Weasels and a habitable trailer constructed on site, were used for an 80 day, 1300 kilometer traverse to conduct the longest traverse carried out by this team: a seismic survey originating from Advanced Base (see figure 6).

\section{South Pole Queen Maud Land Traverses (SPQMLT)}

Between 1964/65 and 1967/68, a reconnaissance traverse was carried out by the USAP to support geophysical and glaciological studies from the South Pole to a 
point roughly in the center of the Queen Maud Land region (specifically at 78.70S, 6.87E). Due in part to the distances involved, this reconnaissance was split over three separate Austral summer seasons: 1964/65, 1965/66, and 1967/68. Scientist on these traverses gathered geophysical measurements (gravity, magnetics, ice thickness), glaciological measurements (ice density, surface hardness, surface features, and a variety of firn measurements), and daily meteorological observations.

During each of these three traverses, the traverse team consisted of eight scientists and two or three "traverse engineers". Three large, special-built Tucker Sno-Cats (two Model 843s and one Model 743) were used for transportation. Two of these Sno-Cats were configured as habitats (the Model 843s; see Figure 7); one was configured as a flat bed and was used as the platform for the ice coring drill (the Model 743). These three Sno-Cats pulled various combinations of three one-ton

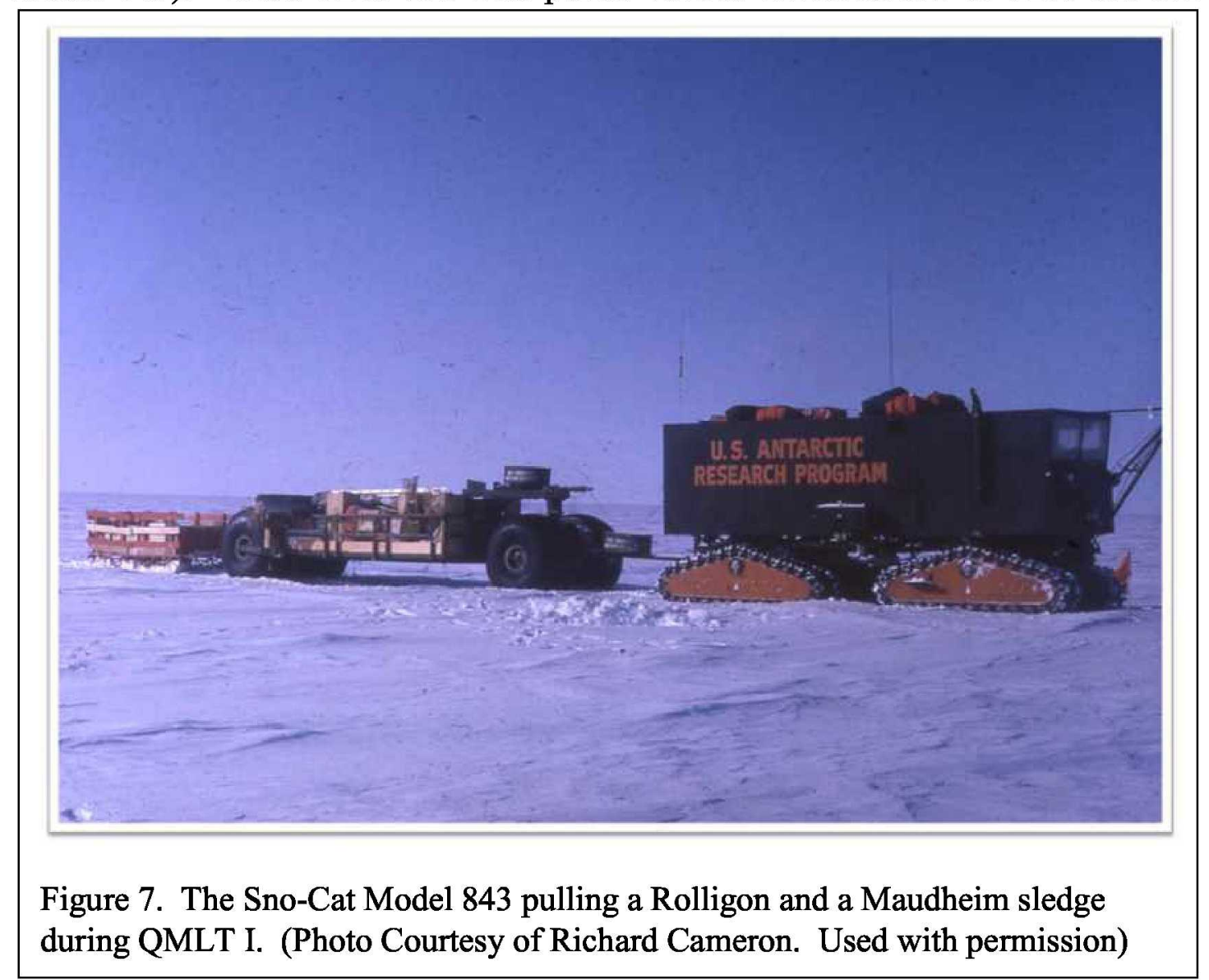

sleds, three two-ton Maudheim sleds, two Rolligon trailers (a trailer with large inflatable tires in which was carried a portion of the fuel for the Sno-Cats). One of these Sno-Cats towing the Rolligon and two other sleds is sown in Figure 7. A typical load on these sleds and trailers was approximately 40,000 pounds (18 metric tons) of supplies, including about 12,000 pounds of fuel, 2,000 pounds of food and 2,000 pounds of explosives. But even with this payload the traverse party required anywhere from one to three airdrops of fuel and supplies.

The first Queen Maud Land Traverse (QMLT I) began at the South Pole (all three Tucker Sno-Cats, sleds, trailers and supplies were flow to the South Pole in Air Force C-130 aircraft) on Dec 4, 1965 and traveled for 54 days to the Pole of 
Inaccessibility (82.11S, 55.03E; the geographical point farthest from any Antarctic coast line); a total distance of 1524 kilometers. QMLT II began with the 11 person crew being flown by $\mathrm{C}-130$ to the equipment stored at the Pole of Inaccessibility on November 22, 1965. After just over three weeks spent working on the Sno-Cats, this team left the Pole of Inaccessibility on December 15, 1965 and traveled for 45 days to the U.S. Plateau Station, a total distance of 1343 kilometers. The final team of 10 people left Plateau Station on December 5, 1967 and travels to a point deep in the Queen Maud Land region (78.70S, 6.87E), a distance of 1556 kilometers. The crew and equipment was loaded on C-130 aircraft and flown back to McMurdo Station. This series of overland traverses ended, in part, due to the success of aerial mapping of the surface (using a variety of sensors) and subsurface (including measuring ice sheet thickness using airborne radar).

These three crews covered a total distance of 4420 kilometers over a total of 152 days, an average of almost 30 kilometers per day. However the actual moving rate would have been faster given that these teams made stops along these traverses to drill ice core, dig snow pits and set off explosive charges to gather seismic data and determine ice depth.

\section{Norwegian-American Scientific Traverse of East Antarctica 2007-2009}

As the name implies, this traverse was a joint effort by U.S. and Norwegian scientists (although there was membership from other countries as well) that was carried out as part of the International Polar Year (IPY). As with the earlier Norwegian-British-Swedish Expedition discussed earlier, neither of these sponsoring groups had sufficient resources to carry out this traverse on their own, but they were able to jointly assemble a team and supporting resources for this important IPY traverse. The overall objective of this traverse was to gather data from the East Antarctic ice sheet from a variety of sources to be used to study the current and past role of this ice sheet in the Earth's climate. This included comparing data sets with those gathered approximately 40 years earlier during the Queen Maud Land Traverse discussed above. The specific science data sets to be gathered by this team included physical, chemical and electrical property analyses of ice laid down at over time (obtained from ice cores) and stratigraphic measurements from recent years (obtained from snow pits). The team also gathered radar data and related it to satellite (particularly Synthetic Aperture Radar or SAR) images. The radar measurements allowed the team to connect data from the snow pits and core samples, as well as mapping near those sites, to the longer traverse.

The traverse team totaled 12 people - seven scientists and five support personnel. This team used the Swedish-built Berco TL-6 "Snow Cat" as its primary means of transportation. Four of these Snow Cats used for the traverse, each vehicle pulling two large (and occasionally a small) sledge. The configuration of these four vehicle/sledge combinations is shown in Figure 8. Prepositioned supply depots (primarily fuel) were used to resupply these vehicles, on both the south bound (three depots) and north bound (two depots, including South Pole Station) traverses.

Figure 9 shows the traverse route followed by this team from the Norwegian station (Troll) to the South Pole (dark blue in this image with science stations 


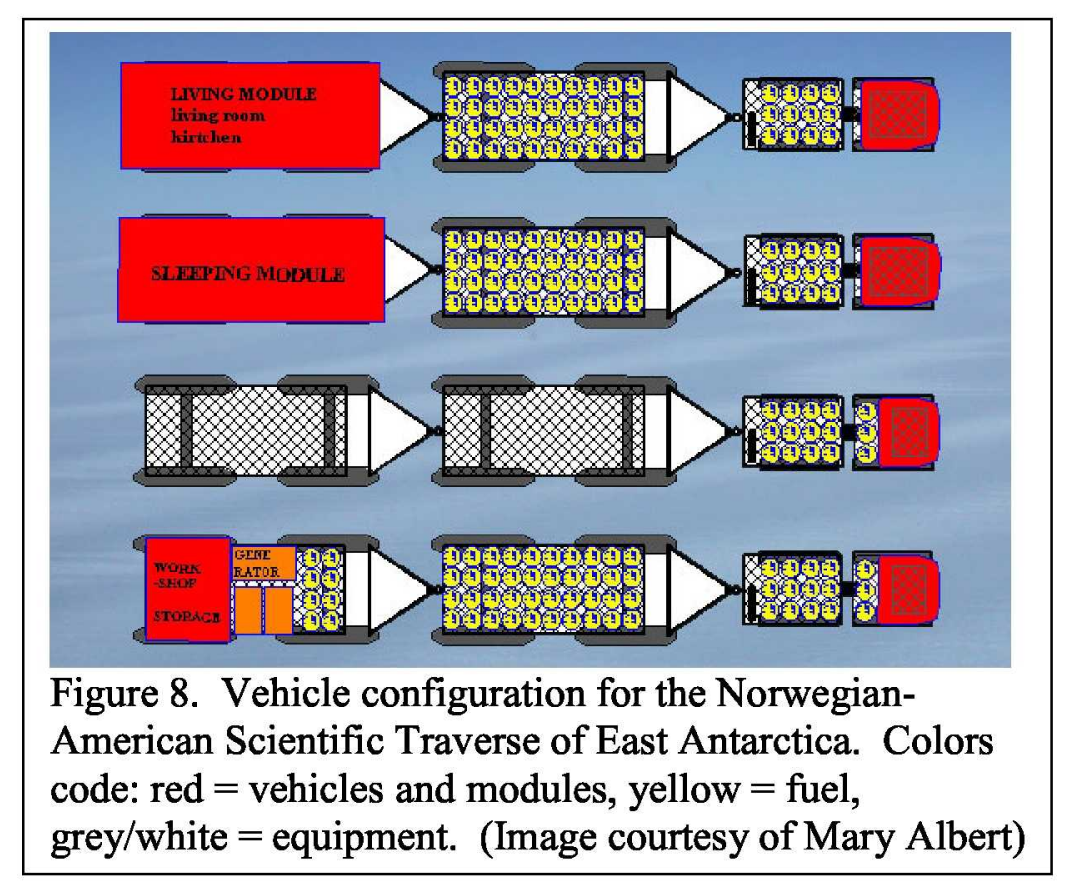

indicated) and the return route (light green in this image). The route from Troll to the South Pole was completed during the 2007-2008 Austral summer and covered a distance of 2676 kilometers in 59 days (an average of 45 kilometers/day). Note: due to recurring mechanical problems with the traverse vehicles, this team actually stopped just short of the South

Pole and was flown the remaining distance. The following season, the traverse team made significant repairs to their vehicles before continuing on to the South Pole and then returning to Troll by a different route. The route from South Pole to Troll was completed during the 2008-2009 Austral summer and covered a distance of 2166 kilometers in 62 days (an average of 34 kilometers/day).

\section{Workshop Results}

There are several conclusions and observations that can be drawn from this workshop: those that are immediately obvious, those that can be developed in the near future and those that will require additional effort to realize.

In this first category, there were several points where NASA plans and the experience of this polar exploration community were similar as well as some important differences.

a) The current approach assumed in the Mars Design Reference Mission for using supply depots along the path of a traverse is consistent with longstanding practice in the polar regions, particularly where air resupply is not available (and there is currently no functional equivalent to airborne resupply available to NASA).

b) Crew sizes in the selected examples are larger than current plans for Mars missions (lunar missions are currently planning on four crew per mission) but there are other examples of similar crew sizes that have functioned quite well for long durations. The crews in these selected missions are large enough to allow for specialization among the members - roughly half scientists and half support personnel - but all members of the crew are expected to help in some manner with all tasks needed to successfully complete the traverse. 
c) Examples

leadership

responsibilities for traverses in these polar regions include some in which a scientist has the primary role, some in which a non-scientist (most of the examples cited involved a military officer) held this primary role, and cases in which this role was divided between a senior scientist and a non scientist. Examples in the first and last categories seemed to work well; the middle case can work, but there were some glaring examples where it did not work well at all. The lesson in this particular area is that selection of the team leadership is extremely important for these long duration missions and for traverses. This does not minimize the

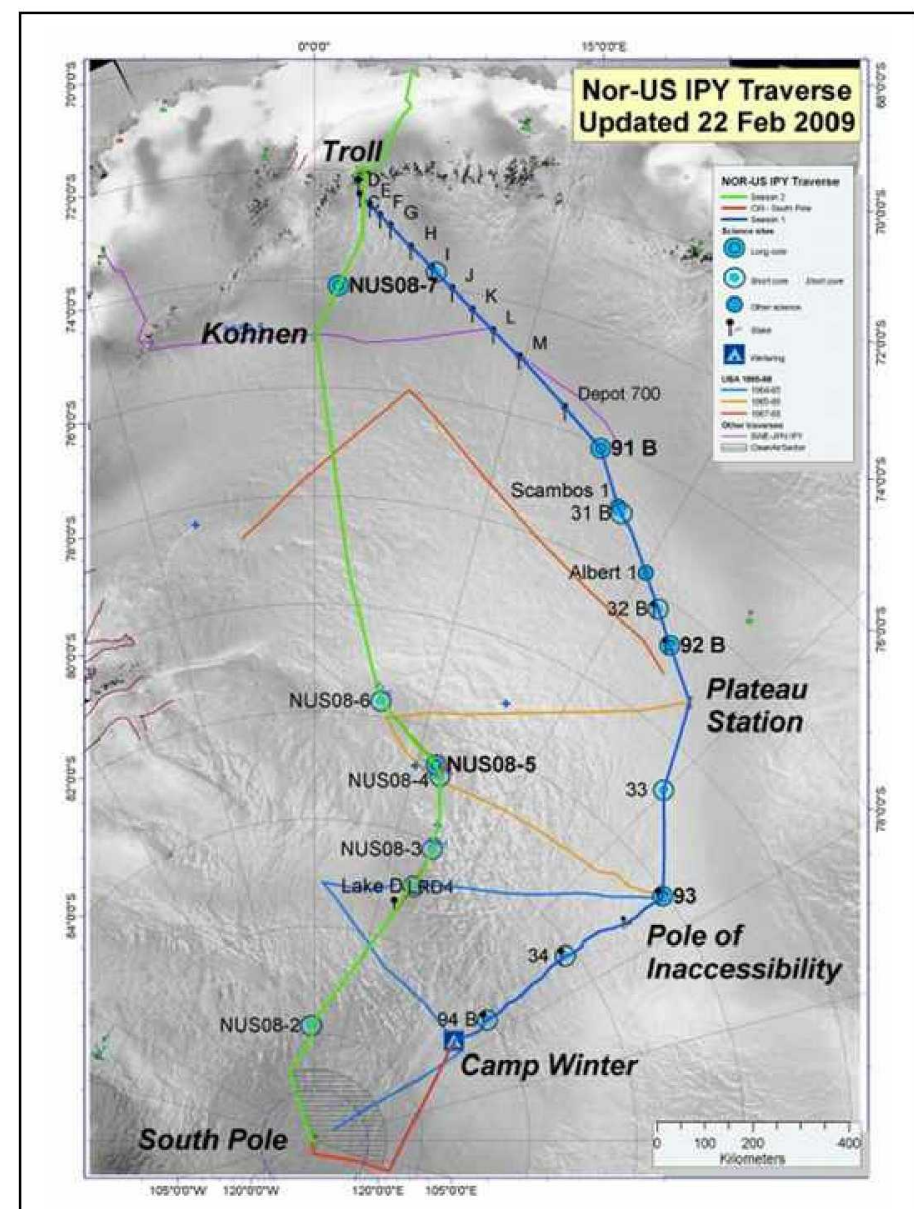

Figure 9. Traverse route for the Norwegian-US Science Traverse of East Antarctica. The dark blue line indicates the 2007/08 route south and the light green line indicates the 2008/09 route north. Also indicated with a light blue-gold-red line are the three QMLT from the mid-1960s. (Map courtesy of Mary Albert. Used with permission.)

importance of selecting all members of the crew such that they will work effectively as a team, but the leadership will be most important in maintaining this cohesiveness and productivity throughout the mission or traverse.

d) Polar exploration has traditionally sent the scientific principal investigator (PI) into the field to conduct their research program. NASA has traditionally trained career crewmembers to be highly skilled at a number of different tasks and in particular to conduct research for a PI while on a space mission. This latter approach has worked quite well for NASA over the years, with the Apollo astronauts cited as well trained field geologists able to work effectively in these new environments but with the support of a highly trained "back room" supporting them from Earth. The point was made that due to the communication lags between Earth and Mars as well as the high potential for 
serendipitous discoveries, that NASA should give serious consideration to modeling crews after the specialization mix seem in polar exploration and training each of these specialists to be able to carry out many of the tasks on the mission. The advantage of having these PI scientists built into the crews from the outset is to use this skill and experience to recognize and take advantage of those serendipitous events that lead to significant discoveries.

In the second category, namely those items that can be developed in the near future, several examples are worth mentioning:

a) There was general agreement that there are potential parallels between key characteristics of the systems used for exploration in these environments, such as heated volume as an analog for pressurized volume or energy usage for various activities. NASA will look at these characteristics to identify which could help with preliminary planning and gather raw data from the presenters to model these characteristics.

b) There was also a realization that there is great potential for high quality data relevant to NASA activities that could be derived from past, present and future exploration the polar regions. However, there is no current requirement to capture these data and analyze them in any manner useful to NASA planning for planetary missions. Several of the workshop participants have taken upon themselves to begin to gather and assess these data. One example is being discussed at this conference in another paper (Mueller, Hoffman, and Thur) in which a detailed inventory of material used by the US Antarctic Program for the South Pole resupply traverses is being generated and assessed. Preliminary results from this particular effort indicate that 1.25 units of mass for transportation, consumables, crew equipment, etc. is required to deliver 1.0 units of mass to the South Pole. This result is highly dependent on the operational approach used to transport these supplies. However it does provide a useful metric for NASA planners to consider as well as providing the USAP with a benchmark they can use to gauge improvements in their resupply approach.

In the third category, those items that will require additional effort to realize, there were a number of general discussions that occurred primarily on the second day of the workshop. New technologies are being applied and design approaches are being tailored to take advantage of these technologies on both side. Interactions between these two communities has begun or is expanding to understand how these new technologies are being leveraged: NASA habitation designers are exchanging ideas and approaches with the Antarctic station designers; Antarctic support contractors have put together a list of areas where NASA could benefit from their experience and vice versa; discussions have begun to compare the equipment used for the NSF South Pole Station resupply traverses to identify possibly functional similarities for NASA. In one specific case, NASA advances in closing the water loop portion of a spacecraft life support system was cited as a technology that could 
be highly beneficial to the USAP now in that it could help significantly reduce the amount of energy used to generate fresh water by melting snow and ice.

On the whole participants in this workshop found the experiences discussed and ideas exchanged to be very useful and should not only be continued, but expanded. These recommendations have been made to management in both communities and plans are underway to implement this general recommendation in a way that will be mutually beneficial.

\section{References}

Anon. (30 August 2004). Development and Implementation of Surface Traverse Capabilities in Antarctica: Comprehensive Environmental Evaluation, National Science Foundation, Washington, DC.

Congress of the United States (30 December 2005). NASA Authorization Act of 2005 (Public Law 109-155), Washington, DC.

Drake, Bret G. (July 2009a). Human Exploration of Mars, Design Reference Architecture 5.0, NASA/SP-2009-566, National Aeronautics and Space Administration, Washington, DC.

Drake, Bret G. (July 2009b). Human Exploration of Mars, Design Reference Architecture 5.0 Addendum, NASA/SP-2009-566-ADD, National Aeronautics and Space Administration, Washington, DC.

Giaever, John (1954). The White Desert, Dutton \& Co., New York.

Swithinbank, Charles (1999). Foothold on Antarctica, The Book Guild Ltd., Sussex, England.

Von Braun, Wernher (1 October 1962). The Mars Project, University of Illinois Press, Urbana, Illinois. 